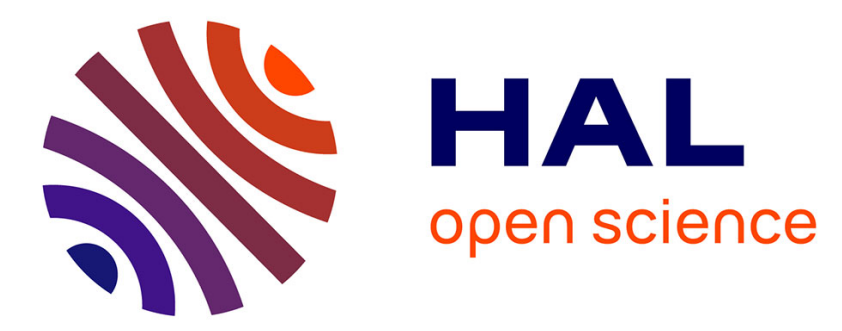

\title{
Muscle function and architecture in children with juvenile idiopathic arthritis
}

Pierre Bourdier, Anthony Birat, Emmanuelle Rochette, Éric Doré, Daniel Courteix, Frédéric Dutheil, Bruno Pereira, Sébastien Ratel, Etienne Merlin, Pascale Duché

\section{- To cite this version:}

Pierre Bourdier, Anthony Birat, Emmanuelle Rochette, Éric Doré, Daniel Courteix, et al.. Muscle function and architecture in children with juvenile idiopathic arthritis. Acta Paediatrica, 2021, 110 (1), pp.280-287. 10.1111/apa.15335 . hal-03024973

\section{HAL Id: hal-03024973 https://hal.science/hal-03024973}

Submitted on 26 Nov 2020

HAL is a multi-disciplinary open access archive for the deposit and dissemination of scientific research documents, whether they are published or not. The documents may come from teaching and research institutions in France or abroad, or from public or private research centers.
L'archive ouverte pluridisciplinaire HAL, est destinée au dépôt et à la diffusion de documents scientifiques de niveau recherche, publiés ou non, émanant des établissements d'enseignement et de recherche français ou étrangers, des laboratoires publics ou privés.

\section{(c)(1)}

Distributed under a Creative Commons Attribution| 4.0 International License 


\section{Muscle function and architecture in children with juvenile idiopathic arthritis}

Pierre Bourdier, ${ }^{1}$ Anthony Birat, ${ }^{1 *}$ Emmanuelle Rochette, $, 2,3,8^{*}$ Éric Doré, ${ }^{1}$ Daniel Courteix, ${ }^{1}$

Frédéric Dutheil, ${ }^{4,5}$ Bruno Pereira, ${ }^{6}$ Sébastien Ratel, ${ }^{1}$ Etienne Merlin, ${ }^{2,3,7}$ and Pascale Duché, ${ }^{1,8}$

\section{Affiliations :}

1. Université Clermont Auvergne, Laboratoire AME2P, CRNH-Auvergne, F-63000 ClermontFerrand, France.

2. Université Clermont Auvergne, INSERM, CIC 1405, Unité CRECHE, CHU ClermontFerrand, Pédiatrie, F-63000 Clermont-Ferrand, France.

3. CHU Clermont-Ferrand, Pédiatrie, Hôpital Estaing, F-63000 Clermont-Ferrand, France.

4. Université Clermont Auvergne, CNRS, Laboratoire de Psychologie Sociale et Cognitive (LaPSCo), UCA-CNRS 6024, CHU, Médecine préventive et occupationnelle, WittyFit, F63000 Clermont-Ferrand, France.

5. Australian Catholic University, Faculty of Health, School of Exercise Science, Melbourne, Victoria 3065 Australia.

6. CHU Clermont-Ferrand, DRCI, F-63000 Clermont-Ferrand, France.

7. Université Clermont Auvergne, INRA, UMR 1019 UNH, ECREIN, F-63000 ClermontFerrand, France.

8. Université de Toulon, Laboratoire IAPS, F-83041 Toulon, France

*. Equal contribution

Running title: Muscular characteristics in children with JIA

\section{Corresponding author:}

DUCHÉ Pascale. Université de Toulon, Laboratoire IAPS, F-83041. Toulon, France, Mobile : +33652183891; Email: pascale.duche@univ-tln.fr

Competing interests: The authors declare no conflict of interest. 


\section{ABSTRACT (194 words)}

Aim: To assess muscle function and functional abilities in children with juvenile idiopathic arthritis (JIA).

Methods: Fourteen children with JIA and 14 healthy controls matched for age and sex were included. Muscle characteristics, both structural (thickness, cross-sectional area (CSA) and fascicle angle) and qualitative (intermuscular adipose tissue : IMAT) were assessed on thigh muscles using ultrasound and peripheral quantitative computed tomography ( $p Q C T)$. Muscle function and functional abilities were determined from the assessment of maximal voluntary isometric contraction force (MVIC) of the knee extensors and vertical jump performance.

Results: No significant difference in MVIC force was observed between both groups. However, squat jump height was significantly reduced in children with JIA $(18.3 \pm 5.4$ vs $24.3 \pm 7.9 \mathrm{~cm}$, $\mathrm{p}<0.05)$. Furthermore, no difference in structural parameters was observed. Nevertheless, IMAT/CSA $\left(0.22 \pm 0.02\right.$ vs $\left.0.25 \pm 0.03 \mathrm{~mm}^{2} ; \mathrm{p}=0.01\right)$ was significantly lower in children with JIA compared to healthy peers.

Conclusion: Muscle dimensions, architecture and function were comparable between children with JIA and healthy children. Only IMAT area was found to be lower in JIA. These outcomes could be associated with a lower physical activity level in children with JIA compared to healthy children.

Keywords: Growth; muscle; IMAT; paediatrics; inflammation 


\section{KEY NOTES (70 words)}

- Despite a lower level of physical activity in children with juvenile idiopathic arthritis, muscle dimensions, architecture and function were comparable to those of healthy children

- Despite treatment's improvement in functional and structural muscular aspects, some qualitative aspects (i.e. muscle lipid storage) seems to persist and contribute to alter metabolic parameters.

- Lower intermuscular adipose tissue in juvenile idiopathic arthritis patients needs further researches with focus on metabolic profile according to the specificities of the pathology (i.e. type, activity and therapy).

\section{INTRODUCTION}

In juvenile idiopathic arthritis (JIA) the pain is due to a chronic inflammatory state induced by an overproduction of pro-inflammatory cytokines such as interleukins (IL) 1 and 6, and tumor necrosis factor alpha. If previous studies have shown that children with JIA have impaired physical fitness (1) and muscle strength (2) compared to healthy children, recent studies observed no significant difference for cardiorespiratory fitness and muscle strength, regardless of sub-types of JIA or disease activity $(3,4)$, probably associated with improvement of treatment. These alterations were mainly characterized by architectural impairments such as decreased muscular thickness (the distance between superior and inferior aponeuroses) $(5,6)$ and fascicle angle (i.e. the angle between the deep aponeurosis and the interspaces among the fascicles) (7). Moreover, muscle mass alteration following chronic inflammation may lead to an increase of the adipose tissue between muscle bundles (intermuscular adipose tissue: IMAT), as observed in adults following muscle injury (8). Indeed, as IMAT is used as a marker of functional and structural muscle impairment (9), it is presumed that patients with inflammatory diseases may have higher IMAT.

Few data are available in the literature regarding the effect of JIA on architectural impairments. 
However, in children with JIA quadriceps muscle thickness was between $90 \%$ and $70 \%$ of normal values in children without and with local arthritis respectively (2). Muscle architecture is a major determinant of force production: muscle cross-sectional area (CSA) is positively correlated to maximal strength (10) due to the quantity of contractile elements contained in the muscle (sarcomeres). The fascicle angle is also an important determinant in force transmission, and so plays a role in strength production (11). An open fascicle angle should allow storage of more contractile material, which plays a role in strength production capacity: however, this effect is under discussion in the literature in different populations (2). These alterations may be observed in monoarticular movements (i.e. leg extension), or in polyarticular movements during ecologic situations such as vertical jumps. For instance, differences in range of motion of lower limbs in children with JIA compared with controls which may be due to joint alterations (12). However, to date, little is still known about the effect of JIA on muscle force production and functional consequences during exercise.

Therefore, the purpose of the present study was to compare architectural parameters (muscle thickness and fascicle angle), muscle CSA, morphological parameters (IMAT) and functional parameters (strength production capacity and vertical jump performance) between children with JIA and healthy peers matched for sex- and chronological age. We hypothesized that compared with their healthy peers, children with JIA would have lower muscle mass and IMAT, and, impaired muscle quality that would result in decreased muscle strength generating capacity and functional abilities (i.e. vertical jump performances).

\section{MATERIALS AND METHODS}

\section{Participants}

Fourteen children aged 8-18 years diagnosed with JIA according to the criteria of the International League of Associations for Rheumatology and 14 healthy children sex- and agematched participated in this cross-sectional study. To be included, volunteers had to perform $\leq 4 \mathrm{~h}$ per week of recreational physical activity and be free of any medical contra-indication to 
physical activity.

Volunteers with diagnosed infection, or who had received oral corticosteroids within the last 3 months or had fever within two weeks prior to enrolment were excluded. For children with JIA, treatments were continued during the study. All treatments had been given for at least 3 months at the time of evaluation. Disease status (active or inactive) was evaluated according to American College of Rheumatology criteria (13).

The study was approved by the governing ethics committee (Comite de Protection des Personnes Sud-Est VI - Clinical trial number NCT 02977416). In accordance with the Declaration of Helsinki of the World Medical Association, all experimental procedures were clearly explained to the participants, who gave their written consent before testing began.

\section{Anthropometric and maturation assessment}

Body mass was assessed to the nearest $0.1 \mathrm{~kg}$ with a digital weight scale. Standing height was measured using a mural stadiometer with the participants barefoot. Body mass index was then calculated as mass $(\mathrm{kg})$ divided by height squared $\left(\mathrm{m}^{2}\right)$. Maturity status was assessed with the Tanner's stage by the hospital pediatrician.

\section{Physical activity level}

Physical activity level was assessed by the French version of the International Physical Activity Questionnaire, which provides an estimate of physical activity levels. Total MET-minutes per week was calculated as is described in previous studies (14). Moderate-to-vigorous physical activity was assessed as activity higher than 3METs (min per day). Physical activity with low intensity was characterized as $<3$ METs (min per day) (such as walking).

\section{Muscle architecture and quality assessment}

Muscle architecture of superficial thigh muscles (rectus femoris, vastus medialis, and vastus lateralis) was evaluated with ultrasound (LogicScan 128 CEXT-1Z, Telemed, Lithuania) using 
an $8 \mathrm{MHz}$ probe (focus $34 \mathrm{~mm}$, depth $60 \mathrm{~mm}$ ). Subjects lay in a prone position on a massage table. The scanning head was coated with water-soluble transmission gel. The probe was applied perpendicularly to the skin with minimal pressure to avoid altering muscle architecture. Cross-sectional area (CSA) of thigh muscles and intermuscular adipose tissue (IMAT) were assessed with peripheral quantitative computed tomography ( $\mathrm{PQCT}$ XCT 3000, Stratec Medizintechnik GmbH, Pforzheim, Germany). The right thigh was placed in the pQCT antenna, so that the femoral condyles were in line with the laser. An antero-posterior scout-view was run to detect the junction between tibial plate and femur, which matched the starting position of the measure. A measure was made at $40 \%$ of the length between the greater trochanter and the mid-patella of the right leg (16). Each tomographic slice was analyzed to obtain soft tissue composition at the level of $40 \%$ of the length using contour mode 3 (threshold, -100 $\mathrm{mg} / \mathrm{cm}^{3}$ ) to locate the skin surface and peel mode 2 (threshold, $40 \mathrm{mg} / \mathrm{cm}^{3}$ ) to locate the subcutaneous fat-muscle boundary. An F03F05 filter was used to remove noise. Soft tissue variables of interest included CSA $\left(\mathrm{mm}^{2}\right)$, IMAT $\left(\mathrm{mm}^{2}\right)$ and subcutaneous adipose tissue (SubFat area in $\mathrm{mm}^{2}$ ).

\section{Muscle strength and functional measures}

Maximal voluntary isometric contraction (MVIC): Volunteers sat on a homemade dynamometer with a hip angle of $40^{\circ}\left(0^{\circ}=\right.$ standing position $)$. The upper body was strapped to the back of the chair and the volunteers were asked to grip the chair to prevent any counter-movements. The right ankle was strapped and connected to a force sensor. After a standard warm-up consisting of repeated isometric contractions of the knee extensors with progressive intensities, volunteers were asked to perform MVIC at different randomized joint angles $\left(29^{\circ}\right.$, $66^{\circ}, 76^{\circ}, 87^{\circ}$ and $103^{\circ}\left[0^{\circ}=\right.$ full extension]) to determine the optimal angle producing maximal force. Two measurements were performed at each angle to check reproducibility. A third trial was performed if the difference between the two measurements exceeded $5 \%$. Subjects were urged to produce maximal voluntary force during isometric contractions. After a resting period 
of $5 \mathrm{~min}$, volunteers then performed two isometric maximal contractions of the knee extensors at the optimal angle (for JIA: $76.3^{\circ} \pm 8.2^{\circ}$ and for healthy children: $68.6^{\circ} \pm 14.4^{\circ}$ ). The two trials were separated by 2 min of recovery. The best trial was retained to obtain MVIC force.

Vertical jump height: The volunteers were asked to perform two squat jumps (SJ) and two counter-movement jumps (CMJ) following standard guidelines. For SJ, the volunteers were to flex their knees at $90^{\circ}$ with hands on hips to prevent counter-movements induced by their arms. The volunteers were to hold this position for 3 s and then jump. The guidelines for CMJ were similar, except that the volunteers were told not to stop between standing and flexing positions. In both exercises, the volunteers were asked to jump as high as possible.

\section{Data analysis}

To assess muscle architecture, two measures were made for muscle thickness and fascicle angle for each muscle, and values were calculated with EchoWave II 3.6.2. software (Telemed, Lithuania). The mean of both values obtained for both pictures was calculated for each parameter. Images acquired with PQCT were treated with Software version 6.20 (Stratec Medizintechnik GmbH, Pforzheim, Germany). CAS, IMAT and the SubFat area were calculated by the formula proposed by Schiferl (17). All the data were acquired and processed by the same investigator to avoid inter-rater bias.

Maximal voluntary isometric force was defined as the maximal force applied on the force sensor. Force data were digitized and exported at analog-to-digital converter rate of $2 \mathrm{kHz}$ PowerLab 8/35; ADInstruments, Bella Vista, NSW, Australia) driven by the LabChart 7.3 Pro software (ADInstrument, Bella Vista, NSW, Australia). Maximal voluntary isometric force was then normalized to muscle CSA to obtain specific force (per unit muscle surface area) and compare the force production between the two groups. 
Flight time duration of both jumps ( $\mathrm{SJ}$ and $\mathrm{CMJ}$ ) was measured by the Optojump system (Microgate, Bolzano, Italy), and vertical jump height was calculated by the software OptoJumpNext (version 1.5.1.0; Microgate, Bolzano, Italy) using the following formula:

$$
h=\frac{T_{f}^{2} \cdot g}{8}
$$

where $h$ is height $(\mathrm{cm}), T_{f}$ is flight time (s) and $g$ the gravity acceleration.

\section{Statistical considerations}

The sample size estimation was determined according to (i) CONSORT 2010 statement, extension to randomized pilot and feasibility trials and (ii) Cohen's recommendations defining effect size bounds as: small (ES: 0.2), medium (ES: 0.5) and large (ES: 0.8, "grossly perceptible and therefore large"). With 14 patients per group, an effect size greater than 1 can therefore be highlighted for a two-sided type-I error at $5 \%$ and a statistical power at $80 \%$.

Statistical analyses were performed using Stata software version 13 (StataCorp, College Station, TX). The tests were two-sided with the type-I error set at $5 \%$. The continuous data were expressed as mean \pm standard deviation according to the statistical distribution. The assumption of normality was assessed with the Shapiro-Wilk test. The comparisons between groups (children with JIA vs. healthy controls) concerning the quantitative parameters (age, maturity status, stature, body mass, muscle thickness and fascicle angle, CSA, IMAT, IMAT / CSA and SubFat area) were performed using the Student $t$-test or Mann-Whitney test when $t$ test criteria were not met. Homoscedasticity was analyzed using the Fisher-Snedecor test. Finally, to express the results, Hedges' effect sizes were estimated with $95 \%$ confidence intervals.

\section{RESULTS}

Characteristics of the population studied are shown in Table 1.

Total weekly energy expenditure and moderate to vigorous physical activity were lower in children with JIA than in healthy children with a moderate effect size of $-0.23, \mathrm{Cl} 95 \%[-0.45$; - 
0.02]. However, time spent in light intensity was similar in both groups (Table 1).

\section{Architectural parameters}

No significant difference for muscle thickness, fascicle angle or thigh CSA was observed between the two groups (Tables 2 and 3). However, there were significant differences regarding values obtained with $\mathrm{PQCT}$ in muscle quality (Table 3). IMAT was not significantly different when compared between the two groups. However, IMAT normalized to CSA was significantly lower in children with JIA than in healthy controls $(0.22 \pm 0.02$ vs $0.25 \pm 0.03$, $p=0.01)$.

\section{Force production and functional outcomes}

Children with JIA and healthy controls did not differ significantly in force generating capacity of the knee extensor muscles $(442.86 \pm 190.49 \mathrm{~N}$ vs. $505.93 \pm 179.04 \mathrm{~N}, p=0.31)$. Furthermore, specific force was similar for the two groups around $0.06 \pm 0.01 \mathrm{~N} . \mathrm{cm}^{-2}$ thigh muscle.

However, functional abilities assessed through polyarticular movement during vertical jump showed lower values in children with JIA compared to healthy children for both squat jump $(18.3 \pm 5.4$ vs $24.3 \pm 7.9, p=0.03)$ and counter-movement jump height $(19.6 \pm 6.7$ vs $25.0 \pm$ 8.2, ns) (Figure 1).

\section{DISCUSSION}

The aim of the present study was to evaluate the effect of JIA on the function and architecture of muscle as well as functional abilities (i.e. vertical jump performance). Our results showed no difference between children with JIA and healthy peers in muscle architecture (muscle thickness, fascicle angle) and muscle CSA. However, pQCT showed a significantly lower IMAT area relative to CSA in children with JIA than in healthy controls.

Assessment of maximal force generating capacity during MVIC did not differ between both groups either, despite decreased performance during vertical jump in children with JIA. 


\section{Structure and quality of muscle in children with JIA}

Regarding knee extensor thickness, no significant difference was found between groups in this study. These results, are not consistent with those obtained before the biotherapies era (8). Thus, no structural impairment was found through fascicle angle. The margin of error of this examination could also explain this discrepancy (18).

Several studies have shown that children with JIA have a lower CSA that healthy children $(19,20)$. In our study no impairment of the muscle in thickness or fascicle angle was observed. However, we found a significantly lower ratio between IMAT area to CSA in the thighs of children with JIA. This unexpected result could be explained by a chronic inflammatory state that may be implicated in the inhibition of insulin signaling by multiple mechanisms (21), leading to insulin resistance. The potential insulin-resistance induced by overproduction of TNF-alpha might thus partially explain the lower IMAT found in children with JIA. Comparison between different individual athletes from different sport disciplines, a higher intramyocellular lipid level in oxidative fiber could be explained by the opposing effects of oxidation into muscle cells and triglyceride uptake from circulation (22). In the same way, during detraining the trained muscle kept a higher myocellular lipid storage than untrained muscle (23). In a previous study, we have shown that children with JIA have a lower lipid oxidation rate during submaximal exercise compared to heathy peers (4). Consequently, the lower IMAT content in children with JIA compared to healthy children could be explained by a lower level of physical activity and an altered oxidative metabolism.

The absence of differences between both groups for structure and mass of muscle could be attributed to current medical treatments that have positive effects on JIA by moderating the inflammation and limiting impairment of muscle mass. Indeed, due to the availability and better use of efficacious therapies - especially methotrexate and biologicals - most children with JIA now achieve a clinical remission. Indeed, in the present study, most patients with JIA were under different medical treatments, sometimes combined ( 5 with TNF blockade, 9 under 
methotrexate, and 4 under non-steroid anti-inflammatory drugs that are known to have adverse effects on muscle mass by inhibition of satellite cell expansion and macrophage numbers) (24). However, their use may contribute to decrease inflammatory levels allowing muscle mass to be maintained. Nevertheless, muscle involvement is a putative long-term determinant of health in persons with inflammatory diseases. Further longitudinal studies are still needed to gain a fuller understanding of the relationship between the disease and its treatment on muscle function in children with JIA.

\section{Muscle function in children with JIA}

The similar muscle size and structure may explain the similar strength measured in the two groups. On the contrary, other studies found a decrease in maximal strength of knee extensors in children with active JIA (25). The results of our study suggest that children with JIA are just as forceful as healthy children during brief maximal voluntary contractions in isometric conditions. However, vertical jump height assessment shows that JIA had an effect on performance during polyarticular dynamic movements. In other words, JIA seems to induce functional impairments in an ecological situation. Because these differences cannot be explained by reduced knee extensor force in children with JIA, it may be related to the biomechanics of jumping. According to kinetic analysis of the lower limb joints (hip, knee and ankle) in children with JIA there is a decrease in torque in both the knee and ankle during takeoff compared with healthy controls, which may result from the muscular weakness reported in the literature and decreased range of motion of the lower $\operatorname{limb}(12)$. Although there is no consensus about the landing, studies suggest that fear of pain may be responsible for different strategies during the jump to limit knee pain at impact, knees commonly being the most sensitive area in children with JIA. As twelve of the fourteen subjects with JIA had knee pain in our study, this explanation seems plausible. This hypothesis is also supported by the fact that children with JIA spontaneously avoid activities with impact such as volley ball or basketball (12). 


\section{Physical activity interest}

One of the main questions arising from these findings is whether the inflammation induced by $\mathrm{JIA}$, or the physical inactivity evoked in the literature (26) is responsible for the decreased performance during vertical jump. Musculoskeletal pain induced by movements may be amplified by the intensity of physical activity. This effect is one of the most often-evoked obstacles to physical activity in children with JIA (26). Thus, medical staff, family and children themselves have historically tended to eschew physical activity, fearing worsened symptoms, pain and fatigue. Recent reviews and meta-analysis observed that children with JIA have a lower physical activity level and a higher sedentary level (27). In the present study, the results of the physical activity questionnaire revealed that children with JIA were less active than healthy children. This outcome may be explained by disease status, which is responsible for the variable levels of pain and is often described as the main obstacle to PA practice (26). Fitness deconditioning and pain in JIA, associated with activity of disease and treatment (3), may also increase exercise perception in children, causing them to rate physical activity as more difficult compared with healthy children (28). In agreement with our previous study (27), only $28.5 \%$ of the presently assessed children with JIA met the physical activity recommendations for public health (29). These results suggest that children with JIA tend to be less active than their healthy peers, in particular in moderate to vigorous physical activity. However, further studies are now needed to gain a better understanding of the effects of inflammation and physical inactivity on muscle function in children with JIA.

\section{Limitations of the study}

Our sample of children with JIA included children with different subtypes of JIA, treatment and disease status did not allow to form subgroups to investigate the effects of JIA more accurately. A supplementary statistical analysis was carried out to compare parameters between children with active disease $(n=7)$ and those with inactive disease $(n=7)$. No significant difference was 
found in the architecture and function of muscle between the two groups, although a large effect size was present for vertical jump performance and physical activity questionnaire score, suggesting a negative effect of the disease activity in children with JIA, according to factors discussed previously. The activity of the disease and the subtype of the rheumatic disease could explain the high variability (3). Disease status is a dichotomous classification established by the clinician and based on the number of painful joints and levels of C-reactive protein (13). Hence further studies are needed to measure cytokines markers and seek relationships with the parameters previously evoked, and thereby gain a better understanding of the effect of chronic inflammation on metabolism and muscle architecture and function.

\section{CONCLUSION}

To conclude, we observed no significant impairment of muscle architecture or function in children with JIA compared with healthy children. However, our results show a lower IMAT area in pathological children's thigh muscle regardless of disease status or treatment, suggesting metabolic disorders induced by JIA. Moreover, vertical jump assessment showed decreased performance in children with JIA. Therefore, muscle characteristics in JIA could not specifically account for reduced functional capacities (e.g. vertical jump performance). This could be attributed to different strategies to avoid pain during polyarticular dynamic activities. Further studies are needed to gain a better understanding of the relationship between inflammation, treatment and physical performance.

\section{ACKNOWLEDGMENTS}

This study did not receive public or private funding. The authors acknowledge all participants for their implication in this study. 


\author{
Abbreviations \\ CMJ: counter-movement jumps \\ CSA: cross-sectional area \\ IMAT: intermuscular adipose tissue \\ JIA: juvenile idiopathic arthritis \\ MVIC: maximal voluntary isometric contraction force \\ MVPA: moderate-to-vigorous physical activity \\ pQCT: peripheral quantitative computed tomography \\ RF: rectus femoris \\ SJ: squat jumps \\ SubFat: subcutaneous adipose tissue
}




\section{REFERENCES}

1. Klepper SE. Exercise in pediatric rheumatic diseases. Curr Opin Rheumatol 2008; 20:619-24.

2. Lindehammar $\mathrm{H}$, Sandstedt $\mathrm{P}$. Measurement of quadriceps muscle strength and bulk in juvenile chronic arthritis. A prospective, longitudinal, 2 year survey. J Rheumatol 1998; 25:2240-8.

3. Risum K, Edvardsen E, Godang K, Selvaag AM, Hansen BH, Molberg Ø, et al. Physical Fitness in Patients with Oligo- and Polyarticular Juvenile Idiopathic Arthritis Diagnosed in the Era of Biologics - A Controlled Cross-Sectional Study. Arthritis Care Res 2018.

4. Rochette E, Bourdier P, Pereira B, Echaubard S, Borderon C, Caron N, et al. Impaired Muscular Fat Metabolism in Juvenile Idiopathic Arthritis in Inactive Disease. Front Physiol 2019; 10:528.

5. de Boer MD, Seynnes OR, di Prampero PE, Pisot R, Mekjavić IB, Biolo G, et al. Effect of 5 weeks horizontal bed rest on human muscle thickness and architecture of weight bearing and non-weight bearing muscles. Eur J Appl Physiol 2008; 104:401-7.

6. Lindehammar H, Bäckman E. Muscle function in juvenile chronic arthritis. $J$ Rheumatol $1995 ; 22: 1159-65$.

7. Kawakami Y, Abe T, Fukunaga T. Muscle-fiber pennation angles are greater in hypertrophied than in normal muscles. J Appl Physiol Bethesda Md 1985 1993; 74:27404.

8. Pagano AF, Demangel R, Brioche T, Jublanc E, Bertrand-Gaday C, Candau R, et al. Muscle Regeneration with Intermuscular Adipose Tissue (IMAT) Accumulation Is Modulated by Mechanical Constraints. PloS One 2015; $10: e 0144230$. 
9. Kim JE, Dunville K, Li J, Cheng JX, Conley TB, Couture CS, et al. Intermuscular Adipose Tissue Content and Intramyocellular Lipid Fatty Acid Saturation Are Associated with Glucose Homeostasis in Middle-Aged and Older Adults. Endocrinol Metab Seoul Korea $2017 ; 32: 257-64$.

10. Freilich RJ, Kirsner RL, Byrne E. Isometric strength and thickness relationships in human quadriceps muscle. Neuromuscul Disord NMD 1995; 5:415-22.

11. Blazevich AJ, Gill ND, Zhou S. Intra- and intermuscular variation in human quadriceps femoris architecture assessed in vivo. J Anat 2006; 209:289-310.

12. Ford KR, Myer GD, Melson PG, Darnell SC, Brunner HI, Hewett TE. Land-Jump Performance in Patients with Juvenile Idiopathic Arthritis (JIA): A Comparison to Matched Controls. Int J Rheumatol 2009; 2009:478526.

13. Wallace CA, Giannini EH, Huang B, Itert L, Ruperto N, Childhood Arthritis Rheumatology Research Alliance, et al. American College of Rheumatology provisional criteria for defining clinical inactive disease in select categories of juvenile idiopathic arthritis. Arthritis Care Res 2011; 63:929-36.

14. Ainsworth BE, Haskell WL, Whitt MC, Irwin ML, Swartz AM, Strath SJ, et al. Compendium of physical activities: an update of activity codes and MET intensities. Med Sci Sports Exerc 2000; 32:S498-504.

15. Hermens HJ, Freriks B, Disselhorst-Klug C, Rau G. Development of recommendations for SEMG sensors and sensor placement procedures. J Electromyogr Kinesiol Off J Int Soc Electrophysiol Kinesiol 2000; 10:361-74.

16. Eser P, Frotzler A, Zehnder $\mathrm{Y}$, Denoth J. Fracture threshold in the femur and tibia of people with spinal cord injury as determined by peripheral quantitative computed tomography. Arch Phys Med Rehabil 2005; 86:498-504. 
17. Frank-Wilson AW, Johnston JD, Olszynski WP, Kontulainen SA. Measurement of muscle and fat in postmenopausal women: precision of previously reported $\mathrm{pQCT}$ imaging methods. Bone 2015; 75:49-54.

18. Ong C, Lee JH, Leow MKS, Puthucheary ZA. Skeletal Muscle Ultrasonography in Nutrition and Functional Outcome Assessment of Critically III Children: Experience and Insights From Pediatric Disease and Adult Critical Care Studies [Formula: see text]. JPEN J Parenter Enteral Nutr 2017; 41:1091-9.

19. Bechtold S, Ripperger P, Dalla Pozza R, Schmidt H, Häfner R, Schwarz HP. Musculoskeletal and functional muscle-bone analysis in children with rheumatic disease using peripheral quantitative computed tomography. Osteoporos Int J Establ Result Coop Eur Found Osteoporos Natl Osteoporos Found USA 2005; 16:757-63.

20. Stagi S, Cavalli L, Signorini C, Bertini F, Cerinic MM, Brandi ML, et al. Bone mass and quality in patients with juvenile idiopathic arthritis: longitudinal evaluation of bone-mass determinants by using dual-energy x-ray absorptiometry, peripheral quantitative computed tomography, and quantitative ultrasonography. Arthritis Res Ther 2014; $16:$ R83.

21. Hotamisligil GS, Murray DL, Choy LN, Spiegelman BM. Tumor necrosis factor alpha inhibits signaling from the insulin receptor. Proc Natl Acad Sci U S A 1994; 91:4854-8.

22. Nagata $\mathrm{Y}$, Takeuchi M, Wu VC-C, Izumo M, Suzuki K, Sato K, et al. Prognostic value of LV deformation parameters using $2 \mathrm{D}$ and $3 \mathrm{D}$ speckle-tracking echocardiography in asymptomatic patients with severe aortic stenosis and preserved LV ejection fraction. JACC Cardiovasc Imaging 2015; 8:235-45.

23. Zhu R, Wen C, Li J, Harris MB, Liu Y-Y, Kuo C-H. Lipid storage changes in human skeletal muscle during detraining. Front Physiol 2015; 6:309. 
24. Mackey AL, Mikkelsen UR, Magnusson SP, Kjaer M. Rehabilitation of muscle after injury - the role of anti-inflammatory drugs. Scand J Med Sci Sports 2012; 22:e8-14.

25. Saarinen J, Lehtonen K, Mälkiä E, Lahdenne P. Lower extremity isometric strength in children with juvenile idiopathic arthritis. Clin Exp Rheumatol 2008; 26:947-53.

26. Limenis E, Grosbein HA, Feldman BM. The Relationship Between Physical Activity Levels and Pain in Children with Juvenile Idiopathic Arthritis. J Rheumatol 2014; 41:34551.

27. Bourdier P, Saidi O, Rochette E, Ratel S, Merlin E, Pereira B, et al. Physical activity and sedentary levels in children with juvenile idiopathic arthritis and inflammatory bowel disease. A systematic review and meta-analysis. Pediatr Res 2019; 86:149-56.

28. Armbrust W, Lelieveld OHTM, Tuinstra J, Wulffraat NM, Bos GJFJ, Cappon J, et al. Fatigue in patients with Juvenile Idiopathic Arthritis: relationship to perceived health, physical health, self-efficacy, and participation. Pediatr Rheumatol Online J 2016; 14:65.

29. Lelieveld OTHM, Armbrust W, van Leeuwen MA, Duppen N, Geertzen JHB, Sauer PJJ, et al. Physical activity in adolescents with juvenile idiopathic arthritis. Arthritis Rheum 2008; 59:1379-84. 


\section{FIGURE LEGEND}

Figure 1. Vertical jump height calculated with Optojump Next.

JIA: juvenile idiopathic arthritis; SJ: squat jump; CMJ: countermovement jump.

Values are mean $\pm S D$. NS: non-significant; *: $p=0.01$ 


\begin{tabular}{|c|c|c|c|}
\hline & $\begin{array}{c}\text { JIA } \\
(n=14)\end{array}$ & $\begin{array}{l}\text { Healthy control } \\
\qquad(\mathrm{n}=14)\end{array}$ & $\mathbf{p}$ \\
\hline Age (yr) & $13.65 \pm 2.77$ & $13.81 \pm 3.17$ & 0.89 \\
\hline Gender (n boys / n girls) & $2 / 12$ & $2 / 12$ & - \\
\hline Tanner's stages $(1-2 / 3-4)$ & $3 / 11$ & $3 / 11$ & - \\
\hline Stature $(\mathrm{cm})$ & $155.3 \pm 4.5$ & $153.6 \pm 4.5$ & 0.79 \\
\hline Body mass (kg) & $45.6 \pm 15.2$ & $46.4 \pm 12.7$ & 0.88 \\
\hline BMI $\left(\mathrm{kg} \cdot \mathrm{m}^{-2}\right)$ & $18.2 \pm 3.3$ & $19.3 \pm 2,3$ & 0.33 \\
\hline \multicolumn{4}{|l|}{ JIA subtype (n (\%)) } \\
\hline oJIA & $5(35.7 \%)$ & - & \\
\hline pJIA RF- & $3(21.4 \%)$ & - & \\
\hline pJIA FR+ & $1(7.1 \%)$ & - & \\
\hline$E R A$ & $2(14.3 \%)$ & - & \\
\hline psoriatic & $2(14.3 \%)$ & - & \\
\hline undifferentiated & $1(7.1 \%)$ & - & \\
\hline Disease duration - months & $49.1 \pm 32.3$ & - & \\
\hline \multicolumn{4}{|l|}{ Disease activity $\dagger(\mathrm{n}(\%))$} \\
\hline Active [TNF-alpha blockade] & $7(50 \%)[2]$ & - & \\
\hline Inactive [TNF-alpha blockade] & $7(50 \%)[3]$ & - & \\
\hline \multicolumn{4}{|l|}{ DMARDs (n $(\%))$} \\
\hline NSAIDs & $4(28.6 \%)$ & - & \\
\hline$M T X$ & $9(64.3 \%)$ & - & \\
\hline TNF-alpha blockade & $5(35.7 \%)$ & & \\
\hline Adalimumab & $1(7.1 \%)$ & - & \\
\hline Etanercept & $4(28.6 \%)$ & - & \\
\hline \multicolumn{4}{|l|}{ Physical Activity } \\
\hline MET-min/week & $1755.2 \pm 2018.1$ & $2633.5 \pm 1637.42$ & 0.046 \\
\hline$M V P A(\min / d a y)$ & $30.3 \pm 41.8$ & $69.1 \pm 67.3$ & 0.015 \\
\hline Light PA (min/day) & $21.2 \pm 24.6$ & $20.6 \pm 21.7$ & 0.865 \\
\hline
\end{tabular}

Table 1. Characteristics of study participants

JIA: juvenile idiopathic arthritis; BMI: body mass index; oJIA: oligoarticular; pJIA RF-/RF+: rheumatoid factor-negative/positive polyarticular JIA; ERA: enthesis-related arthritis; psoriatic: psoriatic JIA; DMARDs: disease-modifying antirheumatic drugs; MTX: methotrexate; NSAIDs: nonsteroidal anti-inflammatory drugs; MVPA: moderate to vigorous physical activity. Values are mean $\pm S D$ or percentage.

$\dagger$ according to Wallace et al. (2011) 


\begin{tabular}{|c|c|c|c|c|c|}
\hline \multicolumn{6}{|c|}{ Muscle thickness (mm) } \\
\hline & $\begin{array}{c}\text { JIA } \\
(n=14)\end{array}$ & $\begin{array}{l}\text { Healthy children } \\
(\mathrm{n}=14)\end{array}$ & $\mathbf{p}$ & Hedge's g & {$[95 \% \mathrm{CI}]$} \\
\hline Vastus lateralis & $18.34 \pm 4.10$ & $20.42 \pm 5.80$ & 0.28 & 0.40 & {$[-0.33 ; 1.12]$} \\
\hline Vastus medialis & $26.38 \pm 5.24$ & $24.95 \pm 6.51$ & 0.53 & -0.23 & {$[-0.95 ; 0.49]$} \\
\hline Rectus femoris & $19.35 \pm 4.55$ & $19.53 \pm 4.15$ & 0.92 & 0.04 & {$[-0.68 ; 0.76]$} \\
\hline \multicolumn{6}{|c|}{ Fascicle angle $\left(^{\circ}\right)$} \\
\hline & $\begin{array}{c}\text { JIA } \\
(n=14)\end{array}$ & $\begin{array}{c}\text { Healthy children } \\
(\mathrm{n}=14)\end{array}$ & $\mathbf{p}$ & Hedge's g & {$[95 \% \mathrm{CI}]$} \\
\hline Vastus lateralis & $17.90 \pm 3.07$ & $18.68 \pm 3.03$ & 0.51 & 0.25 & {$[-0.48 ; 0.97]$} \\
\hline Vastus medialis & $14.95 \pm 5.19$ & $16.73 \pm 4.53$ & 0.34 & 0.35 & {$[-0.38 ; 1.08]$} \\
\hline Rectus femoris & $14.08 \pm 2.96$ & $15.49 \pm 4.00$ & 0.30 & 0.39 & {$[-0.34 ; 1.11]$} \\
\hline
\end{tabular}

Table 2. Values of muscle thickness and fascicle angle obtained by ultrasound.

$J I A=$ juvenile idiopathic arthritis. Values are mean \pm standard deviation. 


\begin{tabular}{lccccc}
\hline \hline & JIA & Control & & & \\
& $(n=14)$ & $(n=14)$ & $\mathbf{p}$ & Hedge's g & [95\% CI] \\
\hline CSA $\left(\mathrm{mm}^{2}\right)$ & $7174.70 \pm 2793.11$ & $8408.85 \pm 3050.73$ & 0.15 & 0.41 & {$[-0.34 ; 1.15]$} \\
IMAT $\left(\mathrm{mm}^{2}\right)$ & $1616.13 \pm 712.85$ & $2166.51 \pm 1058.16$ & 0.07 & $\mathbf{0 . 5 9}$ & {$[-0.17 ; 1.33]$} \\
IMAT / CSA & $0.22 \pm 0.02$ & $0.25 \pm 0.03$ & $\mathbf{0 . 0 1}$ & $\mathbf{1 . 0 0}$ & {$[0.21 ; 1.77]$} \\
SubFat area $\left(\mathrm{mm}^{2}\right)$ & $3258.52 \pm 1324.34$ & $3498.17 \pm 1349.53$ & 0.70 & 0.17 & {$[-0.56 ; 0.91]$} \\
\hline \hline
\end{tabular}

Table 3. Parameters of quality of muscle obtained with pQCT.

CSA: cross sectional area; IMAT: intermuscular adipose tissue; SubFat area: subcutaneous adipose tissue. Values are mean \pm standard deviation. 